\title{
Conteúdo geoelétrico do lixão da capital de Boa Vista, Roraima, Brasil
}

\author{
Souza, L. S. B. *, LAGMAE-UFRR; Andrade, G. G., UFRR
}

Copyright 2018, SBGf - Sociedade Brasileira de Geofísica

Este texto foi preparado para a apresentação no VIII Simpósio Brasileiro de Geofísica, Salinópolis, 18 a 20 de setembro de 2018. Seu conteúdo foi revisado pelo Comitê Técnico do VIII SimBGf, mas não necessariamente representa a opinião da SBGf ou de seus associados. É proibida a reprodução total ou parcial deste material para propósitos comerciais sem prévia autorização da SBGf.

\section{Resumo}

Na porção sul do estado de Roraima, lixão da capital Boa Vista, foram executadas medidas de resistividade elétrica a partir de sondagens elétricas verticais, sendo distinguido dois grupos geoelétricos. O grupo 1 as porções não contaminadas com valores resistividades representativas a Formação Boa Vista e aos depósitos fluviais das planícies de inundação do igarapé Auaí Grande: arenito $(30.000<\rho a<10.000 \Omega \mathrm{m})$, arenito com matriz argilosa $(10.000<\rho a<5.000 \Omega . m)$, siltito $(5.000<\rho a<1.000 \Omega . m)$ e argilito $(1.000<\rho a<700 \Omega . m)$. $O$ grupo 2 faixas contaminadas com anomalias condutivas $(36<\rho a<250 \Omega$.m) relacionadas à pluma de contaminação do lixão e zonas condutivas $(250<\rho a<500 \Omega . m)$ equivalendo à migração da pluma.

\section{Introdução}

Nas sociedades urbanas e/ou rurais a destinação do lixo (resíduos sólidos- RS) é feita quase sempre em quaisquer terrenos baldios, desde que estes sejam relativamente longe das residências. Assim, ainda estamos muito longe de conscientizar a sociedade (pessoas físicas e/ou jurídicas) a importância ambiental, social e econômica do lixo.

Os aterros sanitários, que apesar de serem locais específicos para alocação dos RS, nem sempre a disposição final dos resíduos é realizada de maneira correta, por vezes, desprezando as condições mínimas exigíveis para o funcionamento do aterro, tornando-se áreas sujeitas à propagação de contaminantes (lixões a céu aberto). Nos contaminantes provenientes do lixo, destacam-se os compostos orgânicos que sofrem decomposição bacteriana, devido à umidade desprendemse e arrastam consigo substâncias sulforadas, nitrogenadas e cloradas tóxicas formando um líquido escuro e de odor desagradável (chorume). As estações chuvosas marcam momentos de intensa percolação de água nestes depósitos, bem com o grau de porosidade, proporcionando intensa lixiviação do chorume na forma de pluma em direção às águas subterrâneas. Junto ao chorume, ocorre o arraste de substâncias inorgânicas como os cátions de $\mathrm{Mg}, \mathrm{Na}, \mathrm{Ca}$ e $\mathrm{NH}_{3}$, e de íons de metais pesados de Al, Cd, Pb e Hg (Schalch et al., 1992).

No Brasil, as prefeituras são responsáveis pela coleta e destino final do lixo, cuja a administração pública deve levar em conta as características da cidade e as vantagens e desvantagens de cada processo, antes de dispor o lixo em qualquer área, mobilizar o cidadão e induzi-lo a participar de todas as etapas do processo de manejo e tratamento de seus resíduos (Lima, 2005).

O dimensionamento espacial em profundidade da contaminação resultante pelo destino incorreto do lixo é amplamente mapeado por ferramentas geofísicas, buscando caracterizar e monitorar os contaminantes, eventualmente, presentes no solo, possibilitando um prognóstico quanto à direção de fluxo e aos possíveis efeitos ao meio ambiente (Gallas et al., 2005).

A grande maioria dos estados brasileiros não se adequaram as Normas Brasileiras de construção de aterro sanitário. Portanto, o que se tem são verdadeiros lixões que ainda estão longe de serem realmente extintos pelas prefeituras. Assim, no estado de Roraima desde a sua capital, Boa Vista, até os outros municípios, como por exemplo, Caracaraí, Rorainópolis, Bonfim, Iracema e Mucajaí o que impera são os lixões à céu aberto.

Boa parte do Estado, principalmente a porção centronorte, está recoberta por uma vasta cobertura sedimentar cenozoica, denominada de Formação Boa Vista (siltitos, argilito, arenitos, conglomerados e concreções lateríticas) (Reis et al., 2003; Souza \& Carvalho, 2017a). O caráter essencialmente sedimentar da área (capital Boa Vista) e o fácil acesso, contribuíram ao bom desempenho da metodologia geofísica. Desta forma, foi conduzido o mapeamento preliminar do comportamento elétrico da contaminação advinda do lixão da capital Boa Vista. Este está localizado na BR-174, quilômetro 494, a $11 \mathrm{~km}$ da capital (Figura 1), onde é despejado um montante de 300 $\mathrm{kg} /$ dia de lixo sem qualquer tratamento. Tal comportamento implicará numa possível tendência de contaminação dos corpos hídricos que cortam a capital, e que deságuam na Bacia Hidrográfica do Rio Branco, principal rio que corta o Estado (NE-SW) e formado pela bifurcação dos rios Uraricoera e Tacutu, 


\begin{tabular}{|l|}
\hline O MUNICÍPIO \\
1 BONFIM \\
3 MUCAJAI \\
4 IRACEMA \\
5 CARACARAI \\
6 RORAISTA \\
ॠ Lixão do município de \\
Boa Vista \\
(área de estudo) \\
BR 174 \\
\hline
\end{tabular}

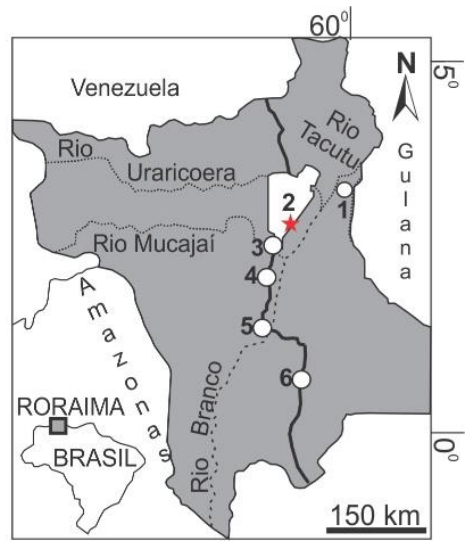

Figura 1-Mapa de localização da área de estudo.

\section{Metodologia}

O desenvolvimento deste trabalho tomou como base a utilização de ferramentas diretas (sensoriamento remoto$\mathrm{SR}$ ) e indiretas (sondagem elétrica vertical-SEV com arranjo schlumberger).

Os produtos de sensoriamento remoto utilizados consistiram nas imagens do satélite landsat 8 , disponíveis pelo Serviço Geológico Americano (earthexplorer.usgs.gov) e pelo software Google Earth Pro. As imagens do Serviço Geológico Americano foram adquiridas em 23/09/2013, georreferenciadas e corrigidas referente à cena 232/058 (órbita/ponto). Os produtos do Google Earth Pro consistiram em imagens de outubro/2014, estas processadas nos programas ArcGis e $E N V I$, resultando em um mapa de drenagem para a área (Figura 2A-B)

Os ensaios eletrorrestivo totalizaram 26 SEV ocorrendo entre os 21-27/01/2015 (Figura 3). No trabalho de campo utilizou-se um resistivímetro. Para maior detalhamento de cumprimento da metodologia pode ser localizado em Braga (2016), Kearey et al. (2009), Orellana (1972), Paranis (1971), Paranis \& Orellana (1970), Souza (2005), Telford et al. (1990), entre outros. Os dados elétricos foram processados utilizando os programas IPIWin2 e Surfer.

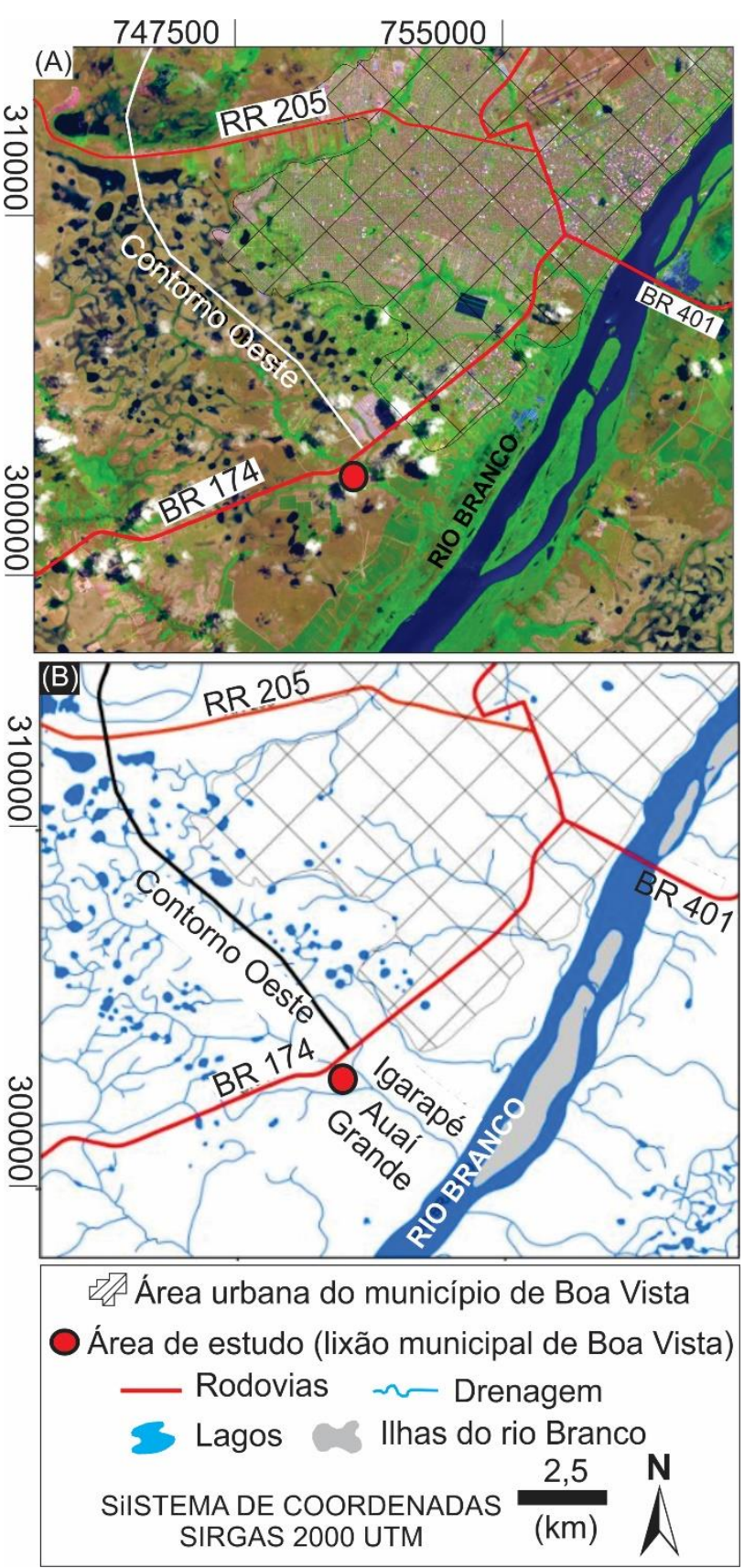

Figura 2-Mapas da área. (A) Imagem de sensoriamento remoto. (B) Mapa de drenagem. 


\section{Resultados}

As curvas de resistividade elétrica $\left(\rho_{a}\right)$ foram reunidas em dois grupos, de acordo com o local de realização dos ensaios, faixa de variação da resistividade e geometria da curva. O grupo 1 abrange 14 levantamentos eletrorresistivos (SEV's 6, 14-26), efetuados nas porções $\mathrm{N}, \mathrm{NE}, \mathrm{E}, \mathrm{SE}, \mathrm{S}, \mathrm{SW}$ e W ao entorno do lixão, com leituras atingindo $24 \mathrm{~m}$ de profundidade (Figura 3). As $\rho_{a}$ deste

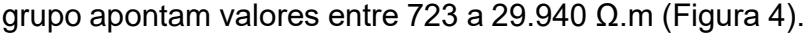

O grupo 2 abrange 12 ensaios (SEV's 1-5, 7-13), executados nas porções NW, N e NE da área (Figura 3), com leituras alcançando profundidades de $24 \mathrm{~m}$, com exceção da SEV 9, que alcançou $18 \mathrm{~m}$. Os levantamentos foram divididos em três subgrupos (2A, 2B e 2C) (Figura 5). O subgrupo $2 A$ possui $\rho_{a}$ de 36 a $3.312 \Omega . m$ e o subgrupo $2 \mathrm{~B}$ de 72 a $11.040 \Omega . \mathrm{m}$, merecem destaque nestes dois subgrupos as $\rho_{a}$ baixas de 700 a $36 \Omega . m$, determinadas a partir de $10 \mathrm{~m}$ de profundidade (Figura $5 A)$.

As SEV's do subgrupo $2 \mathrm{~A}(4,5,7$ e 11) executadas nas porções NW, norte e NE da área (Figuras 3 e 5). Todos os levantamentos foram realizados com direção paralela as bancadas do aterro, e situaram-se cerca de 5 a 30 metros próximos das mesmas. As sondagens conferiram as zonas superficiais do terreno caráter areno-argiloso a argiloarenoso. As baixas resistividades observadas neste subgrupo são claras conforme aumentada a profundidade, de modo que, em 13 a 24 m nenhuma $\rho_{a}$ é superior a 318 $\Omega . m$.

As SEV's do subgrupo 2B (8, 9 e 10) efetuadas na porção norte da área, nas imediações das bancadas do lixão e da planície de inundação do Igarapé Auaí Grande, cerca de 50 a 60 m e 17 a 60 m, respectivamente. As SEV's 8 e 10 foram executadas sobre terrenos de solos arenoargilosos, enquanto, a SEV 9 em areno-argilosos a argiloarenosos (Figuras 3 e 5 ).

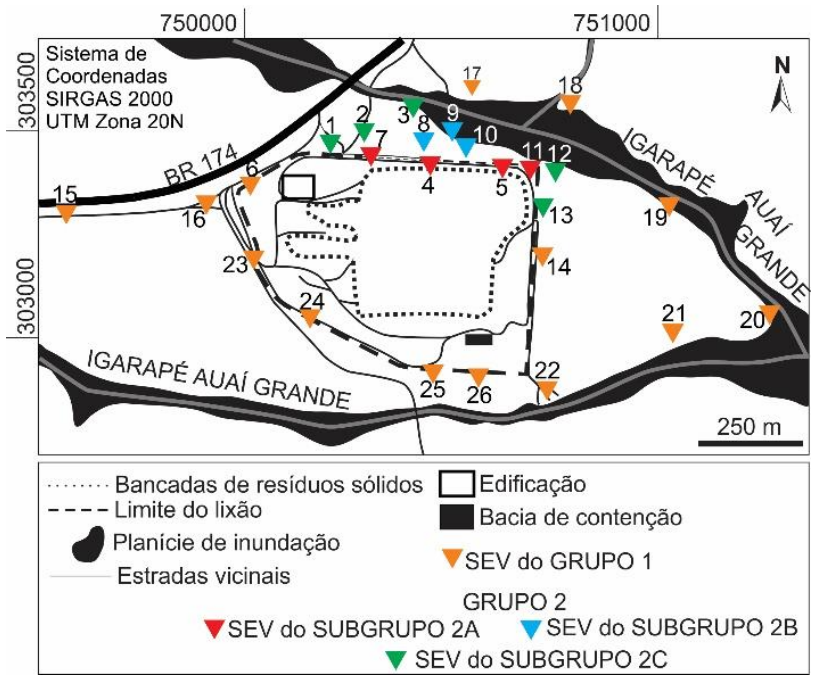

Figura 3-Mapa de pontos das sondagens elétricas verticais (SEV).

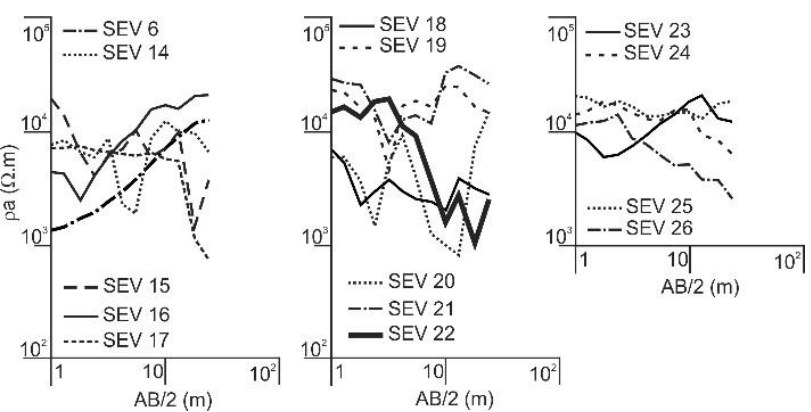

Figura 4-Curvas de SEV do grupo 1.

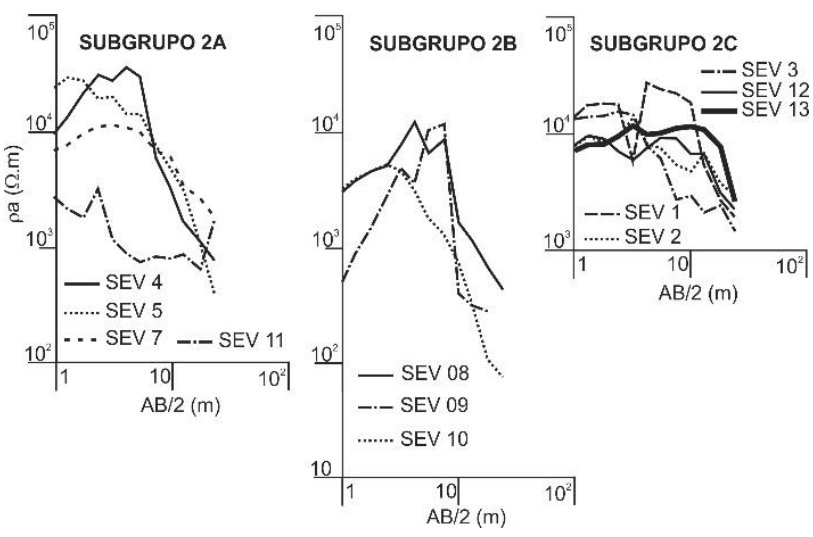

Figura 5-Curvas de SEV do grupo 2.

\section{Discussão e Conclusões}

O comportamento físico da área de estudo caracterizou assinaturas elétricas que foram vinculadas ao contexto geológico e geofísico da região. Os valores de resistividades variam de acordo com o material geológico em subsuperfície (Braga, 2007; Gallas et al., 2005). As resistividades aparentes altas são atribuídas às camadas arenosas, enquanto, as baixas as camadas argilosas. Tais atributos foram associados na área a atitude sedimentar da Formação Boa Vista (arenitos, arenitos arcoseanos, siltitos, conglomerados e concreções lateríticas) (REIS et al., 2003). No entanto, em áreas contaminadas, como a de lixões, a resposta elétrica do material geológico tende a diminuir bruscamente, com valores de $\rho_{a}$ até dez vezes menores que o normal (Braga, 2007; Souza et al., 2017; Souza \& Carvalho, 2017b).

As resistividades do grupo 1 assinalaram valores entre 723 a $29.940 \Omega$.m, correspondendo ao contexto geológico da Formação Boa Vista e dos depósitos fluviais provenientes das planícies de inundação do Igarapé Auaí Grande, possibilitando descrever quatro zonas de resistividades distintas para a geologia da área: arenosa $\left(30.000<\rho_{a}<\right.$ 
$10.000 \Omega . m)$, areno-argilosa (10.000 $\left.<\rho_{a}<5.000 \Omega . m\right)$, argilo-arenosa $\left(5.000<\rho_{a}<1.000 \Omega\right.$.m) e argilosa $(1.000$ $\left.<\rho_{a}<700 \Omega \cdot m\right)$.

O comportamento geoelétrico do grupo 2 demonstrou que - subgrupo $2 \mathrm{~A}$ as resistividades baixas são correlacionáveis as zonas contaminadas, sugerindo assinaturas condutivas. Isto ocorre por conta dos contaminantes associados ao chorume que reduzem expressivamente a resistividade, pois favorecem a condução de corrente elétrica por serem ricos em íons, devido o chorume atacar os metais contidos nos resíduos (GALLAS et al., 2005). O subgrupo 2A foi tratado como a pluma de contaminação $\left(250<\rho_{\mathrm{a}}<36 \Omega\right.$.m) e o subgrupo $2 \mathrm{~B}$ as regiões migratórias dos contaminantes $\left(700<\rho_{a}<\right.$ $250 \Omega$.m). A pluma é constatada nas regiões próximas as bancadas de descarte de resíduos do lixão (cerca de 5 a $30 \mathrm{~m}$ ), devendo-se provavelmente a migração dos contaminantes para as camadas inferiores, pois a característica arenosa e, por conseguinte porosa, permite a percolação dos contaminantes, que se acumulam nos materiais dominantemente argilosos, em virtude da baixa granulometria, porosidade e impermeabilidade.

$\mathrm{O}$ subgrupo $2 \mathrm{~B}$ referente à zona migratória dos contaminantes, encontra-se em uma região intermediária entre o lixão e o Igarapé Auaí Grande. A migração é influenciada por: (1 ${ }^{a}$.) desnível altimétrico da área com cotas de $80 \mathrm{~m}$ para o lixão e $70 \mathrm{~m}$ para o Igarapé Auaí Grande, permitindo a migração dos fluidos (contaminados ou não) por ação gravitacional (Halliday et al., 2009); e ( $2^{\mathrm{a}}$.) fluxo subterrâneo, no qual, durante os períodos de chuva nas planícies de inundação a difusão da pluma é intensa, por conta da oscilação do nível do lençol freático, uma vez que no período de estiagem este nível varia de 1 a 4 m (Ávila, 2007) no município de Boa Vista. Na SEV 10, o valor de $\rho_{a}$ de $72 \Omega$.m em $24 \mathrm{~m}$ de profundidade insinua um estágio mais avançado de migração, indicando uma interligação dos contaminantes pelo fluxo subterrâneo.

Os subgrupos $2 \mathrm{~A}$ e $2 \mathrm{~B}$ implicam que a pluma está concentrada nas porções NW, $N$ e $N E$ e seus contaminantes tendem a migrar a NE da área de estudo, em direção ao Igarapé Auaí Grande (Figura 3). Estes dois subgrupos estão limitados pelo subgrupo 2C (zona resistiva considerada como trapa natural aos contaminantes), influenciados pelo relevo (limite NE, 2000 $<$ pa $<7000 \Omega$.m) e pelas planícies de inundação (limite

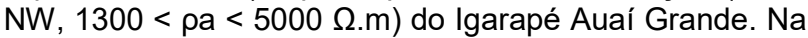
porção sul do igarapé não foram identificadas anomalias condutivas, aludindo que os contaminantes não migrem para esta porção por permanecerem na mesma cota altimétrica lixão.

As Normas Brasileira para construção de aterros sanitários determinam as condições mínimas de proteção apropriada das coleções hídricas superficiais e subterrâneas próximas. Contudo, deste o projeto, a implantação e a operação do chamado aterro sanitário municipal de Boa Vista não houve qualquer preocupação quanto aos impactos ao meio ambiente, não se enquadrando em absolutamente nenhuma das Normas, pois a localização de um aterro deve estar no mínimo a uma distância de 200 $\mathrm{m}$ de qualquer corpo hídrico. Fato este, descumprido na capital roraimense, visto que, o aterro (designação erroneamente dada pela prefeitura de Boa Vista) dista aproximadamente $100 \mathrm{~m}$ do igarapé Auaí Grande, sendo o mesmo construído na bifurcação deste corpo hídrico, e em alguns momentos essa distância chega a diminuir mais ainda alcançado $50 \mathrm{~m}$. Cabe salientar, que este igarapé desagua no principal rio do estado de Roraima (rio Branco) que é o maior abastecedor do Sistema Aquífero Boa Vista, podendo ocasionar impacto ambiental em escala local e, em tempo futuro, regional.

\section{Agradecimentos}

Ao grupo de pesquisa Caimbé (Geociências de Roraima).

\section{Referências}

ÁVILA ISS. 2007. Caracterização preliminar do subsolo da área urbana de Boa Vista-RR, a partir de sondagens de simples reconhecimento. Dissertação (Mestrado em Recursos Naturais) -Universidade Federal de Roraima, Boa Vista, 2007. 91pp.

BRAGA ACO. 2016. Geofísica aplicada: métodos geoelétricos em hidrogeologia. Oficina de Texto, São Paulo, 159pp.

BRAGA, A. C. O., 2007. Métodos Geoelétricos Aplicados nos Estudos de Captação e Contaminação das Águas Subterrâneas. Disponível em: http://www.rc.unesp.br/igce/aplicada/geoeletricos-V4.pdf. Acesso em: 12 març. 2017.

CHRISTENSEN THL, KJELDSEN P, NJERG PL, JENSEN DL, CHRISTENSEN JB. BAUN A., ALBRECHSTEN, H \& HERON G. 2001. Biogeochemistry of landfill leachate plumes. Applied Geochemistry, (16): 659-718.

GALLAS JDF, TAIOLI F, SILVA SMCPD, COELHO OW \& PAIM PSG. 2005 Contaminação por chorume e sua detecção por resistividade. Rev. Bras. Geof., 23 (1): 51-59.

HALLIDAY D, RESNICK R \& WALKER J. 2009. Fundamentos da Física: gravitação, ondas e termodinâmica: v. 2, 8ª Edição, Editora LTC, Rio de Janeiro, 312pp.

KEAREY, P., BROOKS, M., HILL, I., 2009. Geofísica de Exploração: 1ª . Ed.: 1-438, Oficina de Textos. São Paulo.

LIMA LMQ. 2005. Remediações de lixões Municipais aplicações da biotecnologia. São Paulo: Hemus Livraria, Distribuidora e Editora.

ORELLANA E. 1972. Prospeccion geoelétrica en corriente contínua. Madrid: Paraninfo, 523pp.

PARASNIS DS. 1971. Geofisica minera. Ed. Paraninfo, Madrid, 375pp. 
PARASNIS DS \& ORELLANA E. 1970. Princípios de geofísica aplicada: v. 1. Ed. Paraninfo. Madrid/Espanha, 208pp.

SCHALCH V, LEITE WCA, AGUIAR EM \& JÚNIOR JLF. 1992. Aterro Sanitário: Considerações Sobre Escolha do Sítio, Projeto, Implantação, Operação e Monitoramento. 7ํำ Congresso Brasileiro de Águas Subterrâneas, São Paulo, 1992. $5 \mathrm{p}$.

SOUZA LSB. 2005. Mapeamento de aquíferos na Cidade de Manaus (AM) - utilizando Perfilagem Geofísica de Poço e Sondagem Elétrica Vertical. Dissertação (Mestrado em Geofísica) - Centro de Pós-Graduação de Geofísica, Universidade Federal do Pará, Belém (PA), 2005. 84pp.

SOUZA LSB, ANDRADE GG \& MORAES G. 2017. Geofísica rasa em área de despejo de resíduos sólidos, município de Caracaraí/RR. In: CONGRESSO DA ASSOCIAÇÃO BRASILEIRA DE ESTUDOS DO QUATERNÁRIO, 16, 2017a, Bertioga/SP, Anais... Bertioga, ABEQUA, <http://www.abequa.org.br/anais2017> Acesso em: 01 nov. 2017.

SOUZA LSB \& CARVALHO FWS. 2017a. Comportamento elétrico do Sistema Aquífero Boa Vista na área do bairro Distrito Industrial Governador Aquilino Mota Duarte (Boa Vista/RR). In: CONGRESSO DA ASSOCIAÇÃO BRASILEIRA DE ESTUDOS DO QUATERNÁRIO, 16, 2017a, Bertioga/SP, Anais... Bertioga, ABEQUA, <http://www.abequa.org.br/anais2017> Acesso em: 01 nov. 2017.

SOUZA LSB \& CARVALHO FWS. 2017b. Contextualização geológica da porção sudoeste do Sistema Aquífero Boa Vista, estado de Roraima, Brasil, a partir de sondagens elétricas verticais rasas. Bol. Mus. Para. Emílio Goeldi. Cienc. Nat., 12 (1): 91-107.

REIS NJ, FRAGA LM, FARIA MSG \& ALMEIDA ME. 2003. Geologia do Estado de Roraima, Brasil. Géologie de La France, (2-4): 121-134.

TELFORD WM, GELDART LP \& HERIFF RE. 1990. Applied geophysics. Sec. Edition, Cambridge, Cambridge University

Press,

770pp. 